\title{
A SEMIÓTICA LÍQUIDA DO PINGUIM: UM MERGULHO NA ANÁLISE TRIÁDICA DO @PONTOFRIO
}

The liquid semiotics of penguin: a deep dive into the triadic analysis of @pontofrio

La semiótica líquida del pingüino: análisis de la terceridad en la@pontofrio

\section{Andrea Olympio de Mello}

Pontifícia Universidade Católica de São Paulo, São Paulo, Brasil.

Mestre em Comunicação e Semiótica pela Pontifícia Universidade Católica de São Paulo. Professora do curso de Publicidade e Propaganda da Fundação Armando Álvares Penteado.

E-mail: andreaomello@gmail.com

RESUMO Análise semiótica feita a partir da tríade peirceana do case brasileiro de retail digital da empresa Ponto Frio na rede social digital Twitter em busca das estratégias sígnicas utilizadas pela marca.

PALAVRAS-CHAVE Signo, Ponto Frio, Internet, Propagação.

ABSTRACT A semiotic analysis made from Peirce's triad regarding the Brazilian digital retail case of Ponto Frio company in the social media platform Twitter in search of signical strategies used by the brand.

KEYWORDS Sign, Ponto Frio, Internet, Spreading.

RESUMEN Desde la terceridad de Peirce se realizó un análisis semiótico del digital retail, case brasileño en la red social de Twitter de Pontofrio, en búsqueda de estrategias sígnicas utilizadas por la marca.

PALABRAS CLAVE Signo, Ponto Frio, Internet, Difusión. 


\section{INTRODUÇÃO}

O presente artigo é uma análise exploratória fruto de uma incursão recente feita por mim, sua autora, no universo semiótico de Charles Sanders Peirce e, por isso, encontra-se descolado das pesquisas e publicações anteriores que contaram com a minha participação. Segundo Santaella (2002, p. 10), na visão no filósofo, fenomenologista e semioticista, "quaquer coisa que esteja presente à mente tem a natureza de um signo. Signo é aquilo que dá corpo ao pensamento, às emoções, reações etc.”. Portanto, o simples fato desse artigo encontrar-se desarticulado do contexto das publicações anteriores já carrega em si um significado e, dessa forma, funciona e possui a qualidade de signo, neste caso um índice, que indica a ruptura com uma linha de raciocínio, campo e objeto de pesquisa traçados anteriormente. Mas é importante ressaltar que essa mudança de rota não se dá por discordâncias, e sim pela confluência rumo a uma evolucão da pesquisa anterior, que agora está inserida em um novo contexto comunicacional. Se, passados dez anos do mestrado, a pesquisadora não é mais a mesma, então, por que a pesquisa deveria ser? Nesse momento exploratório de novos rumos e signos, tive a oportunidade de assistir a algumas aulas da disciplina Semiótica e Rituais de Consumo, ministrada pela professora Dra. Clotilde Perez no Programa de Pós-Graduação em Ciências da Comunicação da Escola de Comunicação e Artes da USP. Este artigo foi inspirado no trabalho de conclusão da disciplina e em discussões feitas em sala de aula.

\section{UM SEQUESTRO METODOLÓGICO}

Antes de iniciar a análise do objeto de estudo desse artigo, gostaria de desviar o leitor de seu caminho principal para analisar, primeiro, as implicações e relações indiciais estabelecidas pela escolha do corpus, visto que esse é o primeiro processo de comunicação e criação de sentido originários desta pesquisa.

O meio de comunicação escolhido, como primeiro recorte a ser feito no processo de definição do corpus, foi a internet. E, embora muitas vezes o recomendado nesse processo de escolha seja seguir tendências ou utilizar a razão e bagagem acadêmica que possuímos para nos direcionar, preciso confessar que a paixão e o encantamento pelo meio escolhido falaram mais alto. Estudar um meio de comunicação que surgiu recentemente (poucas décadas atrás), está em processo de expansão e descoberta do seu potencial simbólico e desencadeou uma série de mudanças na forma como nos comunicamos, trabalhamos, nos divertimos, pensamos e criamos sentido, é mais do que uma escolha racional. É uma paixão que surge à primeira vista diante de tantas novas possibilidades (d)e descobertas.

Além disso, a internet puxou o gatilho da mudança para muitas outras áreas e mercados, não só para a indústria da comunicação; sua tecnologia somada à democratização de acesso a ela tornou possível o surgimento de novos produtos (como os smartphones e e-books), novos sistemas (como o wi-fi) e novas plataformas de comunicação nunca antes imaginadas (basta você lembrar quantas vezes por dia usa o seu e-mail ou qualquer uma das muitas redes sociais on-line). E mesmo ciente da minha leviandade ao fazer a afirmação a seguir sem possuir o estudo ou conhecimento necessário para embasá-la, nessa introdução me revoguei o direito de fuga de todos os processos metodológicos aprendidos e apreendidos na academia: acredito que a revolução semiótica causada pela internet 
ainda esteja apenas em seu início, e pouco conseguimos apalpar ou compreender além da superfície sensível que se apresenta para nós nas telas de nossos computadores ou smartphones. Começamos há pouco tempo a mergulhar nesse universo e compreender a grandiosidade do seu pontencial e do impacto que pode causar em nossas vidas.

O território simbólico da web também tem proporcionado encontros simbólicos que antes não seriam possíveis. Encontros de linguagens, de plataformas de comunicação e o encontro das marcas com seus consumidores fora de um ambiente comunicacional gerido exclusivamente pelo anunciante, como acontece no ambiente midiático tradicional dos anúncios de revista, filmes publicitários exibidos na televisão e materiais de merchandising implementados nos pontos de venda. Espaços comprados pelas marcas para se comunicarem com seus consumidores e que, pelo simples fato de serem comprados, se tornam territórios partidários onde o diálogo, e como consequência um encontro verdadeiro, é simplesmente impossível.

Dentre os milhares de endereços eletrônicos e plataformas de comunicação que a web disponibiliza para uma marca, o Twitter foi escolhido por dois motivos. Primeiro, ele é uma plataforma que não faz diferenciação entre pessoa física e jurídica na formatação do perfil ou página criada pelo usuário. Ao contrário do Facebook e do Snapchat, que possuem um formato de comunicação específico para marcas e empresas (o Facebook com a sua Fanpage e o Snapchat com seus canais na sessão Discover), com funcionalidades, recursos e até mesmo uma identidade visual diferente, o Twitter não possui tal distinção. Embora ele já possua formatos comerciais como os Trending Topics, a formatação da página de perfil ainda não se tornou alvo de mudanças para aumentar a rentabilidade da plataforma. Assim, o perfil e suas funcionalidades são as mesmas, não importando se o autor pretende fazer uso social ou comercial da plataforma. Tal condição coloca as marcas e empresas presentes no Twitter em pé de igualdade com seus consumidores, incentivando um processo de comunicação e relacionamento mais pessoal. Além disso, após um período de reificação da imagem durante o império massificante da televisão na última metade do século XX, e com o apogeu dos anúncios sem texto invadindo as páginas dos anuários de propaganda do país no início do século XXI, o Twitter (não apenas, mas também ele) resgatou o apetite appeal e a "interessância" da linguagem verbal escrita, ressaltando inclusive o caráter discreto desse legi-signo. Com o Twitter, escrever voltou a ser cool, desde que sejam no máximo 140 caracteres.

O perfil @pontofrio foi escolhido por ser o primeiro grande case de retail digital nacional. O Ponto Frio foi a primeira marca brasileira a conseguir articular sua comunicação em uma plataforma de mídias sociais (normalmente utilizada para construção de relacionamento com o cliente) para gerar vendas, sustentando sua estratégia em longo prazo, sem ficar refém de promoções e ações táticas pontuais sazonais, como o Black Friday, por exemplo. "Em uma época em que encontrar a linguagem certa para falar com o consumidor na internet ainda é um desafio para as empresas, a marca se tornou um dos cases de sucesso justamente por adotar uma linguagem simples, informal e engraçada” (AGUILHAR, 2012), adicionando novas variáveis além do preço à equação das vendas no meio digital.

Para realizar um recorte do corpus que possibilitasse sua análise, o perfil @pontofrio foi acessado no dia 19 de novembro de 2015, e os cinco posts posicionados no topo da página, junto com sua diagramação, 
foram selecionados como amostra representativa do universo simbólico do Pinguim.

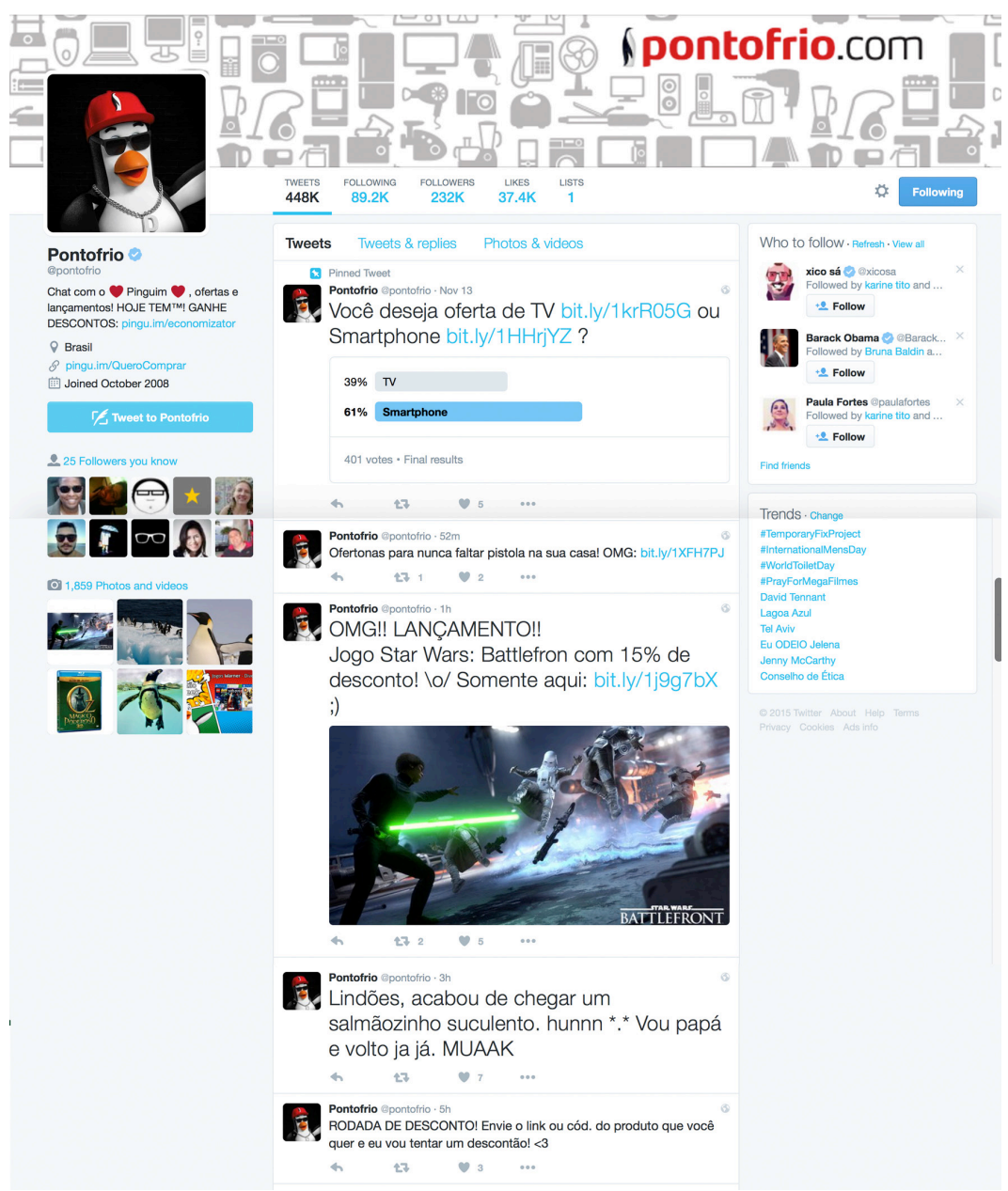

Figura 1. Amostra.

Fonte: https://twitter.com/pontofrio. Acesso em: 19 nov. 2015

\section{NA SUPERFÍCIE DO SIGNO AINDA HÁ AR}

Ao iniciar esta análise, meu maior desejo era conseguir limpar a minha vista da mesma forma que limpo o cache do meu navegador, para evitar o condicionamento cerebral e preconceitos já estabelecidos de quem conhece o seu objeto de estudo de longa data. Ah... Se eu pudesse lembrar como foi acessar o endereço twitter.com/pontofrio pela primeira vez, como quem olha um quadro ou uma obra de arte sem a necessidade de adorá-lo simplesmente porque conhece a importância histórica do seu autor... A superfície sensorial do signo é a sua membrana mais sensível e também a porta de entrada para todo pontencial comunicador que ele guarda, pois "É a qualidade apenas que funciona como signo, e assim o faz porque se dirige para alguém e produzirá na mente desse alguém alguma coisa como um sentimento vago e indivisível” (SANTAELLA, 2004, p. 63).

Então, se por um instante aquietarmos nosso ímpeto de análise e julgamento para contemplarmos a página do perfil @pontofrio no Twitter como quem olha para um quadro ou um objeto novo pela primeira vez, perceberemos que as cores frias tomam conta deste espaço comunicacional - seu fundo é azul claro e no topo da página temos 
grafismos e desenhos na cor cinza sobre um fundo branco insípido -, o que poderia evocar um sentimento de distanciamento ou impessoalidade. Mas isso simplesmente faz com que o toque de vermelho na logomarca Ponto Frio, no boné do Pinguim e nos corações do perfil chamem a atenção e ganhem destaque diante da multiplicidade de informação, trazendo uma presença calorosa para a marca nesse primeiro contato com seu consumidor ou internauta.

A imagem do Pinguim no avatar da página é descolada e cool, com uma pose informal e usando acessórios da moda polular. Mas para um visitante que acessa a página pela primeira vez e ainda não conhece o personagem, o uso dos óculos escuros pode despertar um certo sentimento de desconfiança, pois não conseguimos ver seus olhos. Tal sensação logo passa ao percorrermos as imagens dos posts, abrindo espaço novamente para a aspiração trendy na cena 3D de luta ou combate de um game que vemos no terceiro post da página, reforçando a percepção de marca cool criada pelo avatar.

A grande quantidade de textos curtos e fragmentados e as pequenas fotos nas laterais da página sinalizam o excesso de informação ali contido e disponível com um simples scroll down ou clique do mouse. Sintoma da fragmentação e overload de dados que a internet nos trouxe e que, na primeiridade do signo, ganha forma em uma poluição visual que causa ressaca aos olhos fatigados do internauta.

A primeiridade está na superfície do signo; na tríade signo-objetointerpretante ela está no signo mesmo, visto que ele é o ponto de contato e intermediador do objeto e do interpretante com o mundo durante o processo de comunicação. Como uma colcha de retalhos que se estende sobre a cama, o Twitter se esparrama pelos domínios da web, e cada perfil criado nele ajuda a criar essa superfície sígnica. 0 @pontofrio é um pequeno retalho dessa colcha, um sin-signo navegando em um mar de informação e conexões, pois "qualquer coisa que se apresente diante de você como um existente singular, material, aqui e agora é um sin-signo" (SANTAELLA, 2004, p. 65-66).

E enquanto sin-signo, a página do Ponto Frio no Twitter é um canal específico de comunicação da empresa que pertence tanto ao universo simbólico da marca quanto ao universo simbólico da plataforma Twitter. E é o fato de ser um sin-signo posicionado na interseção de dois universos simbólicos tão diferentes que confere ao @pontofrio a potência de uma semiose peculiar e própria, mais autoral e menos engessada pelas normas e leis desses dois mares em que navega, ora se aproximando e ora se afastando de cada um deles.

Essa potência subversiva, localizada na interseção sígnica entre a institucionalização da marca e o caráter pessoal das redes sociais, pode ser tangibilizada de muitas formas diferentes, ou até mesmo ignorada, como muitas empresas fazem ao criarem perfis em redes sociais digitais simplesmente para ocupar esse território comunicacional, ou ao adotarem nesses canais a mesma lógica e estratégia de comunicação que usam nos meios de massa. O Ponto Frio conseguiu transformar essa potência em vantagem ao ceder o espaço de fala do seu perfil para alguém com um tom mais próximo e pessoal, como é característico do Twitter, mas que também possui a força institucional da marca.

Quem fala em nome da empresa é o Pinguim, personagem que sempre foi associado ao Ponto Frio, mas que ganhou vida própria na internet. É ele quem publica as promoções, oferece descontos e até 
sugere produtos para os seguidores, sempre antenado com os últimos memes e tendências da internet. (AGUILHAR, 2012)

A formatação visual imposta pela página do Twitter com sua restrição de 140 caracteres delineia as regras do universo simbólico da plataforma, e a força institucional da marca Ponto Frio, assim como suas normas de aplicação, pode ser percebida na cartela de cores do @pontofrio e no tom de voz adotado nos posts. Essas são estratégias de comunicação seguidas por muitas empresas ao criarem seus perfis no Twitter e elaborarem o conteúdo a ser postado em suas páginas. Mas o entendimento de que a plataforma proporciona um território mais pessoal e menos institucionalizado para a comunicação entre marcas e consumidores e, inclusive, que esse não é o tipo de comunicação ou conteúdo que os internautas procuram nesse canal, abriu para o Ponto Frio a possibilidade de criar uma estratégia diferente.

\section{O OBJETO APREENDIDO DENTRO DO SIGNO}

O potencial comunicador de um signo reside na sua conexão com o objeto que ele representa ou intenciona comunicar. Sem essa ponte, é impossível chegar a um interpretante para completar a tríade sígnica. E, para entender melhor a força da estratégia adotada pelo Ponto Frio, é preciso analisar e remover cada uma das camadas que levam à semiose do signo com seu objeto, percorrendo seus caminhos icônicos, indiciais e simbólicos.

"O objeto do ícone [...] é sempre uma simples possibilidade do efeito de impressão que ele está apto a produzir ao excitar nosso sentido. [...] Qualquer qualidade tem, por isso, condições de ser um subsituto de qualquer coisa que a ele se assemelhe" (SANTAELLA, 2004, p. 64). Na parte superior da página do Ponto Frio no Twitter (header), temos os desenhos de eletrodomésticos e eletroeletrônicos criando uma padronagem ou estampa gráfica. Além disso, o desenho bidimensional do pinguim na logomarca pontofrio.com serve de vestígio para a origem do personagem Pinguim, representado no avatar da página e que ganha voz nos posts publicados.

Mas, por ser uma possibilidade, a relação icônica nos deixa na superfície de uma semiose que começa a transbordar. Mergulhamos então um pouco mais em busca das certezas que as relações indiciais trazem.

Enfim, o índice como real, concreto, singular é sempre um ponto que irradia para múltiplas direções. Mas só funciona como signo quando uma mente interpretadora estabelece a conexão em uma dessas direções. Nessa medida, o índice é sempre dual: ligação de uma coisa com outra. (SANTAELLA, 2004, p. 66)

A relação indicial dos desenhos de eletrodomésticos e eletroeletrônicos no header da página deixa claro que esse perfil pertence a uma empresa, sinalizando inclusive o portfolio de produtos e atuação comercial do Ponto Frio. Já a imagem do Pinguim no avatar da página funciona como um índice que a aproxima do universo simbólico do Twitter, uma plataforma de comunicação onde pessoas físicas podem criar suas páginas ou perfis para se comunicarem com outras pessoas. Ao colocar a imagem do Pinguim em seu avatar (e não uma logomarca, como fazem muitas outras empresas), o Ponto Frio revela que, embora esse seja o perfil de uma pessoa jurídica, pertence também ao universo 
autoral e pessoal do personagem Pinguim, visto que "as mascotes se mostram [...] como espelho das construções múltiplas identitárias humanas, que se transferem às formas subjetivas de expressão das marcas” (TRINDADE, 2011, p. 131).

O simples fato de @pontofrio ser uma página do Twitter já a insere em seu universo simbólico, cheio de normas e regras para formatação da página e publicação de posts. Nesse processo temos o uso predominante de símbolos no processo de comunicação: a linguagem verbal escrita. Para conferir maior realismo e um tom pessoal à fala do Pinguim, o Ponto Frio faz uso recorrente de dialetos que surgiram no ambiente da web, como "lo/" e "OMG".

Outro ponto interessante a ser analisado é que, há alguns anos atrás, identificar @pontofrio como corpus dessa pesquisa não deixaria dúvidas sobre a plataforma a que estávamos nos referindo, visto que a mesma possuía uma relação indicial com a plataforma Twitter. A partir do momento que outras plataformas, como o Instagram, adotaram a notação @pontofrio para identificar seus usuários, a relação entre signo e objeto deixou de ser indicial e passou a ser simbólica.

\section{MERGULHO EM BUSCA DE UM INTERPRETANTE}

A imagem do Pinguim descolado no avatar e o tom da linguagem verbal escrita utilizada nos posts evocam o imaginário de uma empresa e personagem cool, prestativos e íntimos do leitor, tudo ao mesmo tempo e agora.

O universo simbólico cool é construído na imagem do avatar e também no uso das expressões verbais escritas "OMG!", "Lindões”, "MUAAK” e também no uso de símbolos gráficos que fazem parte do alfabeto ocidental para criar "webícones”, como “o/” e “;)".

Podemos perceber a prestatividade do Pinguim nos seguintes trechos extraídos dos posts: "Você deseja oferta de TV [...] ou Smartphone [...]?”, "Envie o link ou cód. do produto que você quer e eu vou tentar um descontão!”. A oferta ou desconto em um produto nunca são colocados no contexto comparativo e hiperbólico do mercado (o melhor preço ou o maior desconto, por exemplo), sua contextualização é feita no relacionamento com o cliente, onde o Pinguim e a Ponto Frio estão sempre a serviço do desconto ou do preço que o cliente deseja, independente deste ser o menor preço a ser pago pelo produto ou não.

Já a intimidade com o leitor da págia é construída com posts em que o Pinguim revela momentos íntimos do seu dia, construindo a percepção de que essa página pertence à pessoa/personagem Pinguim, e não à empresa Ponto Frio. Um exemplo desse tipo de post é "Lindões, acabou de chegar um salmãozinho suculento. hunnn ** Vou papá e volto já já. MUAAK”. O uso do "hunnn", que não é uma palavra e sim uma expressão sonora, reforça essa intimidade, assim como a expressão infantilizada "papá”, em vez da palavra "comer". Esses posts no formato de diário transformam a leitura do perfil @pontofrio em um ritual, mais um a ser inserido na rotina "cybernética" de quem constantemente acompanha a intimidade de celebridades e/ou amigos nas redes sociais:

As formas estabelecidas para os diferentes rituais têm uma característica comum: a repetição ou regularidade de procedimentos. Os rituais, executados e vivenciados repetidamente, conhecidos ou ao menos identificáveis pelas pessoas, concedem certa segurança 
psíquica. Pela familiaridade com as sequências do(s) ritual(is), sabemos o que vai acontecer, os passos são previsíveis e, por meio deles, celebramos nossa solidariedade, partilhamos sentimentos, enfim, é possível vivenciar uma sensação de coesão social. [...] O importante nos rituais não seria necessariamente o conteúdo explícito, mas suas características de forma, convencionalidade e repetição. (PEREZ; TRINDADE, 2014, p. 160).

Assim, os rituais rotineiros do Pinguim promovem não só uma maior veracidade ao tom pessoal e à vida virtual do personagem, mas também fortalecem a conexão emocional com seus leitores e consumidores.

A intimidade que os posts mais pessoais do Pinguim constroem com seu leitor deixa clara a função de relacionamento com o cliente que a página possui, o que aproxima a marca Ponto Frio dos seus clientes e promove maior intimidade. Enquanto isso, o uso da ferramenta da enquete no primeiro post e a publicação de lançamentos e ofertas comunicam que esse também é um canal de vendas.

É essa oscilação de conteúdo nos posts - que ora navegam no universo particular do personagem com uma linguagem “cybernética” irreverente, ora mergulham no oceano mercadológico das ofertas muitas vezes envelopadas por um assunto trendy que tomou conta das discussões nas redes sociais digitais - que aproxima o perfil @pontofrio de seus leitores, os verdadeiros responsáveis pelo grande sucesso do case, visto que “o público tem um papel ativo na 'propagação' de conteúdos, em vez de somente servir como portador passivo da mídia viral: suas escolhas, seus investimentos, seus interesses e propósitos, assim como suas ações, determinam o que ganha valor” (JENKINS; FORD; GREENE, 2014, p. 47).

A comunicação construída pelo Ponto Frio em seu perfil do Twitter conduz seus consumidores e seguidores a estabelecerem uma relação de proximidade e confiança com a marca, por meio da intimidade e subserviência do Pinguim, do conteúdo publicado por ela e suas ofertas. O resultado dessa estratégia foi traduzido financeiramente no fluxo de caixa do Ponto Frio: "O pinguim do Ponto Frio vendeu nada menos do que R $\$ 20$ milhões em 2012 sem qualquer investimento em mídia, usando apenas os seus perfis no Twitter e no Facebook para divulgar as ofertas da rede de varejo" (MELLO, 2013).

\section{CONCLUSÕES}

A página @pontofrio no Twitter se apresenta como um sin-signo indicial. Mas na construção de significado com seu interpretante a marca não seguiu apenas o caminho funcional priorizado por muitas empresas quando elaboram suas estratégias de presença digital em redes sociais. O uso da emoção como estratégia para gerar intimidade e, consequentemente, confiança, foi o grande responsável pela visibilidade alcançada pela página e por abrir um novo caminho para a conversão de vendas, longe da guerra sangrenta pelos menores preços do mercado.

O uso da potência subersiva da página por estar posicionada na interseção simbólica do território institucional e mercadológico da empresa com o território pessoal das redes sociais foi um dos grandes responsáveis pelo sucesso das ofertas (muitas vezes envelopadas em assuntos da moda, trend topics ou memes) e propagação de seu conteúdo e da página. Como bem disse Jenkins, "se algo não se propaga está morto" (JENKINS; FORD; GREENE, 2014, p. 23). 


\section{REFERÊNCIAS}

AGUILHAR, L. Ponto Frio aposta em personagem e bom humor e faz sucesso nas redes. Época Negócios, São Paulo, 27 set. 2012. Disponível em: <https://glo.bo/1i5WqyW>. Acesso em: 14 dez. 2015.

MELLO, B. Pinguim do Ponto Frio: case vende R $\$ 20$ mi pelo Twitter e Facebook. Mundo do Marketing, Rio de Janeiro, 5 ago. 2013. Disponível em: <http://bit.ly/2oVydFZ>. Acesso em: 14 dez. 2015.

JENKINS, H.; FORD, S.; GREENE, J. E. Cultura da Conexão: criando valor e significado por meio da mídia propagável. São Paulo: Aleph, 2014.

PEREZ, C.; TRINDADE, E. Os rituais de consumo como dispositivos midiáticos para a construção de vínculos entre marcas e consumidorez. Revista Alceu, Rio de Janeiro, v. 1, n. 29, p. 157-171, 2014.

SANTAELLA, L. O que é Semiótica. São Paulo, Brasiliense, 2004.

. Semiótica Aplicada. São Paulo, Loyola, 2002.

. Matrizes da linguagem e pensamento: sonora, visual, verbal. 3. ed. São Paulo, Iluminuras, 2005.

TRINDADE, E. O mundo divertido dos mascotes levado a sério. Signos do Consumo, São Paulo, v. 3, n. 1, p. 129-132, 2011. 